\title{
One clutch or two clutches? Fitness correlates of coexisting alternative female life-histories in the European earwig
}

\author{
Joël Meunier · Janine W. Y. Wong • Yamenah Gómez • \\ Sabine Kuttler · Lilian Röllin · Dimitri Stucki • Mathias Kölliker
}

Received: 2 March 2011 / Accepted: 21 July 2011/Published online: 3 August 2011

(C) Springer Science+Business Media B.V. 2011

\begin{abstract}
Whether to reproduce once or multiple times (semelparity vs. iteroparity) is a major life-history decision that organisms have to take. Mode of parity is usually considered a species characteristic. However, recent models suggested that population properties or condition-dependent fitness payoffs could help to maintain both life-history tactics within populations. In arthropods, semelparity was also hypothesised to be a critical preadaptation for the evolution of maternal care, semelparous females being predicted to provide more care due to the absence of costs on future reproduction. The aim of this study was to characterize potential fitness payoffs and levels of maternal care in semel- and iteroparous females of the European earwig Forficula auricularia. Based on 15 traits measured in 494 females and their nymphs, our results revealed that iteroparous females laid their first clutch earlier, had more eggs in their first clutch, gained more weight during the 2 weeks following hatching of the first clutch, but produced eggs that developed more slowly than semelparous females. Among iteroparous females, the sizes of first and second clutches were significantly and positively correlated, indicating no investment trade-off between reproductive events. Iteroparous females also provided more food than semelparous ones, a result contrasting with predictions that iteroparity is incompatible with the evolution of maternal care. Finally, a controlled breeding experiment reported full mating compatibility among offspring from females of the two modes of parity, confirming that both types of females belong to one single species. Overall, these results indicate that alternative modes of parity represent coexisting life-history tactics that are likely to be condition-dependent and associated with offspring development and specific levels of maternal care in earwigs.
\end{abstract}

Keywords Semelparity - Iteroparity - Alternative reproductive tactics · Coexistence · Parental care · Forficula auricularia

J. Meunier $(\bowtie) \cdot$ J. W. Y. Wong · Y. Gómez · S. Kuttler · L. Röllin · D. Stucki · M. Kölliker Zoological Institute, Evolutionary Biology, University of Basel, Vesalgasse 1, 4051 Basel, Switzerland e-mail: joel.meunier@unibas.ch 


\section{Introduction}

Whether the resources available for reproduction are invested in a single reproductive attempt (i.e. semelparity), or partitioned among multiple attempts (i.e. iteroparity), is a critical question in life-history theory (Charlesworth 1994; Charnov and Schaffer 1973; Cole 1954; Ranta et al. 2002; Stearns 1992). Mode of parity is usually considered a species characteristic (Stearns 1992). In line with this view, the early deterministic models for the evolution of modes of parity predicted that either semelparous or iteroparous life-histories would be evolutionarily stable and spread to fixation (Charlesworth 1994; Charnov and Schaffer 1973; Cole 1954; Stearns 1976, 1992). The models predicted that reproductive lifespan of individuals (e.g. age at first reproduction, adult vs. juvenile viability), adult fecundity, extrinsic rates of juvenile and adult mortality (Charlesworth 1994; Stearns 1992) or stochastic risk associated with a single reproductive event (bet-hedging effect, Stearns 1976) influence whether a semel- or itero-parous life-history should evolve in a population. Recently, new theoretical models identified ultimate reasons to explain why semelparous and iteroparous life-history tactics may coexist within populations. In particular, the maintenance of alternative modes of parity may be facilitated in species with structured populations (Ranta et al. 2000a), unstable population dynamics (Ranta et al. 2000b), stochasticity in offspring and adult viability (Ranta et al. 2002) or differential effects of population density on offspring versus parental mortalities (Bulmer 1985). Furthermore, when considered as alternative allocation phenotypes (defined as discontinuous interindividual variation in a trait of interest, Brockmann and Taborsky 2008; Taborsky et al. 2008), semelparous and iteroparous life-histories are also expected to coexist whenever the fitness payoffs of expressing the two alternatives are condition-dependent (Taborsky et al. 2008; Tomkins and Brown 2004).

To date, most empirical work testing factors associated with the evolution of modes of parity (e.g. life-history traits, ecology and fitness payoffs) used comparisons across taxa, related species or populations within species (references listed in Crespi and Teo 2002; Moerkens et al. 2010). Only little empirical research was carried out on semelparous and iteroparous life-history tactics that coexist in a population (Grosberg 1988; Iguchi and Tsukamoto 2001; Leggett and Carscadden 1978; Seamons and Quinn 2010). However, populations with coexisting alternative life-histories are of particular interest because they offer a unique opportunity to understand mode of parity as alternative life-history tactics and to study the ultimate and proximate factors maintaining coexistence. More generally it is possible to investigate in such populations the evolution of parity independently from population idiosyncrasy and its coevolution with other specific life-history or behavioural traits with important fitness consequences, such as parental care (Gilbert and Manica 2010; Stegmann and Linsenmair 2002).

Maternal care is known to have evolved repeatedly in insects and spiders, where it generally provides important benefits to eggs and juveniles (Choe and Crespi 1997). Both across and within species, tending females can express variable duration and complexity of care, ranging from nest building to egg grooming, protection against predators or food provisioning (Choe and Crespi 1997; Mas and Kölliker 2008; Tallamy and Wood 1986). Maternal care may evolve when the associated fitness benefits exceed costs for tending mothers, such as a reduced future reproduction or an increased mortality rate (CluttonBrock 1991). For arthropods, it has been hypothesized that semelparity is a critical lifehistory pre-adaptation for maternal care to evolve (Tallamy and Brown 1999). Because semelparous females pay no cost of care in terms of future reproduction, already small benefits of care to offspring are sufficient for the evolution of maternal care. Based on this 
hypothesis, semelparous females were predicted to provide higher levels of care to current offspring than iteroparous ones (Gilbert and Manica 2010; Tallamy and Brown 1999).

Females of the European earwig Forficula auricularia are known to provide maternal care to eggs and nymphs, and to show a life-history dimorphism in terms of the number of clutches they produce over their lifetime (reviewed in Costa 2006). Maternal care is provided in the form of tending the clutch of eggs and nymphs, supplying food to the nymphs and protecting them against predation (Costa 2006). Females from this species produce either a single clutch (in the following referred to as $1 \mathrm{C}$ ) or two clutches (referred to as $2 \mathrm{C}$ ) where the second clutch is produced without remating. $1 \mathrm{C}$ and $2 \mathrm{C}$ strategies were originally thought to characterize different $F$. auricularia populations (Vancassel 1984) and later as characteristic of potential cryptic sister species (Guillet et al. 2000; Wirth et al. 1998). However, recent work repeatedly showed that $1 \mathrm{C}$ and $2 \mathrm{C}$ females co-occur within populations (in Switzerland, Kölliker 2007; in Italy, Mas and Kölliker 2011). This indicates that both strategies can be maintained within natural populations and calls for further studies both on fitness-related traits associated with mode of parity and the question if $1 \mathrm{C}$ and $2 \mathrm{C}$ life-histories represent one single or two cryptic sister species.

The current study aimed at investigating associations between alternative life history tactics (semelparity and iteroparity) and other life-history, morphological and behavioural traits in the European earwig $F$. auricularia. To this end, we recorded reproductive, morphological and behavioural characteristics of 600 females (and their offspring) sampled in the field and reared under standardized laboratory conditions. If the $1 \mathrm{C}-2 \mathrm{C}$ polymorphism reflects coexisting alternative life-histories with equivalent fitness consequences (Charlesworth 1994; Charnov and Schaffer 1973; Cole 1954), we predicted 1C females to produce a larger clutch than the first clutch of $2 \mathrm{C}$ females, as well as a similar life-time number of offspring, and/or offspring of better quality e.g. by providing more care (measured in terms of nest building, egg guarding, clutch attendance and food provisioning) than $2 \mathrm{C}$ females. Conversely, the polymorphism could represent conditiondependent alternative life-history tactics where poor female condition (e.g. nutritional, physiological, genetic) could limit the production of a second clutch. In this case, we predicted $2 \mathrm{C}$ tactic to reflect better intrinsic conditions and, hence, $2 \mathrm{C}$ females to be able to produce a larger lifetime number of offspring and display higher levels of maternal care. Finally, to confirm that $1 \mathrm{C}$ and $2 \mathrm{C}$ strategies do not characterize sympatric sister species (Wirth et al. 1998) in the studied population, we tested reproductive isolation between offspring from $1 \mathrm{C}$ and $2 \mathrm{C}$ females using cross-breeding of progeny (males and females) from $1 \mathrm{C}$ and $2 \mathrm{C}$ females.

\section{Materials and methods}

Field sampling and laboratory rearing

A total of 600 females and 600 males of the European earwig Forficula auricularia were sampled in May 2009 in Dolcedo, Italy $\left(7^{\circ} 56^{\prime} 55^{\prime} \mathrm{E}, 43^{\circ} 54^{\prime} 14^{\prime} \mathrm{N}\right.$, altitude $\left.443 \mathrm{~m}\right)$. All individuals were setup in the laboratory under standard conditions for random mating for 5 months in 20 plastic containers $(37 \times 22 \times 25 \mathrm{~cm})$, consisting of 30 males and 30 females each. In this species, males and females have multiple mating partners (promiscuous mating system) and clutches are generally sired by multiple fathers (Guillet 2000). All containers were lined with fluon to prevent the escape of the insects, contained humid sand as a substrate, and egg carton and plastic tubes as shelters. The food consisted of an 
artificial diet (composition: $10 \mathrm{~g}$ Agar, $60 \mathrm{~g}$ carrots, $30 \mathrm{~g}$ flower pollen, $30 \mathrm{~g}$ bird food (Schweizer Bekfin, Eric Schweizer SAMEN AG, Thun, Switzerland), $30 \mathrm{~g}$ cat food (Perfect fit $8+$ senior, Wathan, Switzerland) and $900 \mathrm{ml}$ water) and was changed three times a week. The containers were kept in a climatic chamber at 60\% humidity, 10:14 h light:dark cycle and $20: 15^{\circ} \mathrm{C}$ during light and dark periods, respectively (=autumn condition).

After observation of the first oviposition on the 19 of October 2009, all 600 females were isolated in individual Petri-dishes. Each female was subsequently placed in complete darkness at $10^{\circ} \mathrm{C}$ for 1 week to further stimulate oviposition, and then maintained in complete darkness at $15^{\circ} \mathrm{C}$ and $60 \%$ humidity (=winter condition) until egg-laying and hatching. No food was provided from egg-laying to hatching (Kölliker 2007). One day after hatching, females and nymphs were set up in new Petri-dishes. From hatching (=day 0 ) to day 14 , clutches were kept at $60 \%$ humidity, $14: 10 \mathrm{~h}$ light: dark photoperiod and a constant temperature of $20^{\circ} \mathrm{C}$ (=summer condition).

Fourteen days after hatching of the first clutch, females were separated from their nymphs to initiate the production of second clutches. Fourteen days were chosen because it has been reported that female care for nymphs may end early in their second instars, which occurs approximately 12 days after hatching (Lamb 1975). On this day, 20 nymphs per clutch were setup in new Petri-dishes $(14 \times 2 \mathrm{~cm})$ and reared under summer conditions until they were used in mating experiments (see below). Mothers were set up in new Petridishes for oviposition of second clutches. To compare properties of first and second clutches while controlling for environmental effects, Petri-dishes for second clutch production were held under winter conditions for egg-laying and hatching, and then transferred to summer conditions from hatching to day 14. Except when specified, all Petridishes were of $10 \times 2 \mathrm{~cm}$ dimension and contained humid sand, aluminium shelters and ad libitum artificial diet.

Measures of life-history traits, morphology and development

A total of 15 measurements on clutches and mothers were taken during laboratory rearing. Clutch size (eggs and nymphs), hatching success and nymph survival were obtained by counting the number of eggs per clutch 1 day after egg-laying and the number of nymphs per clutch one and 14 days after hatching. Fresh weights of mothers and nymphs on day one and 14 were measured to the nearest $0.001 \mathrm{mg}$ using a MettlerToledo MT5 Micro-balance (Mettler, Roche, Basel). Each mother and a random subsample of usually 10 nymphs were weighed. If the number of nymphs in a clutch was smaller than 10, all the available nymphs were weighed. Embryonic developmental time was defined as the number of days between oviposition and hatching, and the developmental rate of nymphs as the number of days from hatching to the first observation of a second instars nymph in a clutch. Finally, structural body size of females was estimated by measuring their pronotum area, which is strongly correlated to the measure of pronotum width $\left(r^{2}=0.87\right)$ used in other studies (Tomkins and Brown 2004; Tomkins and Simmons 1998). To obtain a measure of pronotum area, we measured pronotum width and length under a binocular scope (Leica, MZ 12.5) to the nearest $0.001 \mathrm{~mm}$ using Image ${ }^{\odot}$ software v1.43n (http://rsb.info.nih.gov/ij/), and calculated the area by multiplying the largest width by the largest length. All characteristics of eggs and nymphs from first and second clutches were measured in a standardised way. 
Measures of maternal care

Four distinct maternal care behaviours were scored for first clutches. (1) Nest building: at egg-laying, the complexity of the nest built by each female was ranked from 1 to 4 . 1 : females laid their eggs without building a nest, 2: they laid the eggs into a small cavity in the sand, 3: females burrowed a small nest to 4: females built a complex nest (i.e., wider crater surrounded by wall-like extensions). (2) Egg guarding: during the daily checks we scored if the female was within a $2.5 \mathrm{~cm}$ radius (=diameter of the experimental nests) of her eggs. Egg-guarding was defined as the proportion of days a female was observed within that radius over the total number of days between egg-laying and hatching. (3) Family aggregation: after hatching we counted the proportion of nymphs within a $2.5 \mathrm{~cm}$ radius of the female's head on days 2, 5, 8, 11 and 14 after hatching. Family aggregation was defined as the average of these five values. Notice that high values of family aggregation were unlikely to be obtained by chance: nymphs form tightly aggregated groups typically located near the mother's head, and not near an arbitrary female body part (J.M., M.K., personal observation) as would be expected in case of spatial proximity that occurs by chance. The measures involved in egg guarding and family aggregation were recorded once a day, between 9:00 and 11:00 am, while these nocturnal individuals were inactive (i.e., during light conditions). (4) Food provisioning: this scoring took place between days 6 and 7 after hatching, a period where mouth-to-mouth contacts between mothers and nymphs are the most frequent (Liu 1991). At day 5, the usual food was removed from each Petri to standardize nutritional condition of nymphs and females, and to increase female foraging behaviour on the subsequent day. On day 6 , mothers were isolated for $1 \mathrm{~h}$ in small Petri-dishes $(5.5 \times 1.2 \mathrm{~cm})$ with humid sand as substrate and a pollen pellet dyed with blue food-dye (synthetic E-131, patent blue V, Werner Schweizer AG, Switzerland, see Staerkle and Kölliker 2008) as food source. After $1 \mathrm{~h}$, mothers were replaced in their original Petri-dish with a standardized group of 20 nymphs (sometimes slightly fewer due to small clutch size: on average $19.65 \pm 2.81$ (mean \pm SD) nymphs). Groups of nymphs were standardized to avoid confounding effects of clutch size on the provisioning score, and food provisioning was not estimated in clutches containing fewer than 10 nymphs. The remainder of nymphs was temporarily set up in another small Petri-dish with humid sand. $15 \mathrm{~h}$ later (overnight), the level of food provisioning was scored as the proportion of nymphs with blue/green gut among all nymphs in the experimental group (see also Mas et al. 2009; Staerkle and Kölliker 2008). After the provisioning experiment, the nymphs previously separated were returned to their original Petri-dish, together with their respective mothers and the remaining nymphs. The labour intensive scoring of food provisioning could only be carried out in a subset of 328 clutches that were chosen haphazardly from the base populations.

Clutches that were not chosen to be involved in the measurement of food provisioning were treated identically (i.e., food was also removed), except for the food provisioning. The developmental rate of nymphs was significantly different between clutches involved in the food provisioning experiments (mean $\pm \mathrm{SE}=23.76 \pm 0.07$ days) and clutches that were not involved $(23.27 \pm 0.06$ days; Welch $t$ test, $t=-5.11, d f=419.147$, $P<0.0001$ ). By contrast, none of the other measured traits were significantly associated with the inclusion of clutches in the provisioning experiment (all $P>0.08$ ). Note that our results did not qualitatively change when excluding/including clutches involved in food provisioning measurements.

Finally, each female was retrospectively categorised as presenting $1 \mathrm{C}$ or $2 \mathrm{C}$ life-history tactic, depending on whether they had produced a single clutch or two clutches in the 
period between day 14 and day 60 . We selected 60 days as temporal delimiter for egg laying because previous work indicated that females were very unlikely to produce a second clutch more than 60 days after egg hatching (Mas and Kölliker 2011). Females laying a second clutch that did not hatch $(N=32)$ were discarded from the analyses as they could not be assigned unambiguously to the $1 \mathrm{C}$ or $2 \mathrm{C}$ tactic. Results did not significantly change when these females were included, irrespectively of their assignment to the two categories.

\section{Cross-breeding among offspring from $1 \mathrm{C}$ and $2 \mathrm{C}$ females}

To confirm that individuals with $1 \mathrm{C}$ and $2 \mathrm{C}$ life-histories represent one single species, we tested for mating compatibility between offspring of the $1 \mathrm{C}$ and $2 \mathrm{C}$ females from the previous experiment. A total of 56 controlled single-matings were conducted between all possible combinations of sons and daughters of $1 \mathrm{C}$ and $2 \mathrm{C}$ females. For these matings, adult sons and daughters were obtained from 51 to 60 randomly chosen first clutches of $1 \mathrm{C}$ and $2 \mathrm{C}$ females, respectively (see above). To ensure virgin status of individuals, males and females of each clutch were separated in two new Petri-dishes of equal size within a maximum of 3-4 days after emergence (during which no fertilizations occur; MK unpubl. results). Two weeks after completed emergence the 56 mating pairs were setup in new Petri-dishes where they were allowed to mate during 3 months. Subsequently, the females were isolated and the standard breeding procedure was used for earwig breeding (see above). In addition, eggs were cross-fostered within and between females with different parity background in order to isolate potential mating incompatibility from other potential incompatibilities such as egg care. Clutch size, hatching success and the body mass of hatched nymphs were recorded as before (see above). If the $1 \mathrm{C} / 2 \mathrm{C}$ polymorphism in $F$. auricularia populations represents coexisting alternative life-history tactics, we expected similar clutch sizes, number of nymphs and body weight of hatched nymphs) for breedingcrosses among parity background as compared to within background (i.e., lack of interaction between $1 \mathrm{C}$ and $2 \mathrm{C}$ backgrounds).

\section{Statistical analysis}

Correlates between female reproductive type (1C or $2 \mathrm{C}$ ) and parameters of first clutches were tested on 494 out of the 600 females $(82.3 \%)$, of which 305 were involved in the scoring of food provisioning. A total of 106 females were excluded because they (1) did not produced a first clutch ( $N=6$ females; $1.0 \%$ of the total number of females), (2) escaped from their Petri-dishes or were mixed by mistake with other clutches during the experiment $(N=18 ; 3.0 \%)$, (3) died during their first clutch $(N=8 ; 1.3 \%)$, (4) had at least one morphological, physiological or behavioural measure that was accidentally unrecorded during the experiment $(N=42 ; 7.0 \%)$, and finally (5) could not be attributed to either $1 \mathrm{C}$ or $2 \mathrm{C}$ reproductive strategies as they produced a second clutch that did not hatch $(N=32 ; 5.3 \%)$. These latter 32 clutches were either eaten by their mother few days after egg laying, suffered from early infection (eggs did not develop and became reddish in coloration) or from late infection (eggs developed but became brownish in coloration).

We tested for differences between $1 \mathrm{C}$ and $2 \mathrm{C}$ females in their reproductive and developmental parameters using two Multivariate Analyses of Variance (MANOVA) where the measured traits (either from the clutches or the mothers, see below) were entered as dependent variables and the reproductive type of females was entered as a fixed factor. The first MANOVA was conducted on "clutch traits" using the entire data set $(N=494$ 
females). This analysis included egg number, hatching success, time of embryonic development, survival rate of nymphs from day 1 to day 14, mean weight of nymphs at day 1 , relative weight gained by nymphs between day 1 and day 14, and developmental rate of nymphs as dependent variables (Table 1). The second MANOVA was conducted on maternal traits using the subsample of females involved in food provisioning measurements ( $N=305$ females) since MANOVA omit objects with missing values (Quinn and Keough 2002). This analysis included laying date of the first clutch, maternal weight at hatching, proportion of weight gained by mothers between day 1 and day 14, pronotum area of mothers and the four measurements of maternal care-nest building, egg guarding, family aggregation and food provisioning — as dependent variables (Table 1). Interpreting which morphological, physiological or behavioural trait contributed significantly to each MANOVA was then tested using independent $t$ tests. To correct for inflated type-I errors due to multiple testing, the significance level $\alpha=0.05$ was adjusted to $\alpha=0.027$ using the False Discovery Rate correction (FDR, Benjamini and Hochberg 1995).

To explore potential trade-offs in female investment between first and second clutches, each of the seven traits measured in both clutches of the $2 \mathrm{C}$ females was compared using paired $t$ tests and Spearman's correlation tests, with $\alpha=0.027$ (FDR correction). Trade-

Table 1 Measures of first clutches of females adopting one-clutch (1C females) or double-clutches strategy (2C females) strategies

$\begin{array}{lllll}1 \mathrm{C} \text { females } & \text { 2C females } & t \text { Values } & d f & P \\ \operatorname{Mean} \pm \operatorname{SE}(N) & \text { Mean } \pm \operatorname{SE}(N) & & & \end{array}$

\begin{tabular}{|c|c|c|c|c|c|}
\hline \multicolumn{6}{|l|}{ Clutch traits } \\
\hline Egg number & $46.92 \pm 1.31(74)$ & $52.47 \pm 0.51(420)$ & -4.2 & 492 & $<0.0001$ \\
\hline $\begin{array}{l}\text { Embryonic developmental time } \\
\text { (day) }\end{array}$ & $23.16 \pm 0.14(74)$ & $23.51 \pm 0.05(420)$ & -2.57 & 492 & 0.011 \\
\hline Hatching success $(\%)$ & $82.32 \pm 2.38(74)$ & $83.83 \pm 0.91(420)$ & -0.64 & 492 & 0.525 \\
\hline $\begin{array}{l}\text { Nymphs survival from day } 1 \text { to } \\
\text { day } 14(\%)\end{array}$ & $88.53 \pm 1.28(74)$ & $88.40 \pm 0.48(420)$ & 0.61 & 492 & 0.540 \\
\hline Nymph's weight at day 1 (mg) & $1.39 \pm 0.03$ & $1.40 \pm 0.01$ & -0.72 & 492 & 0.473 \\
\hline $\begin{array}{l}\text { Weight gained by nymphs until } \\
\text { day } 14(\%)\end{array}$ & $122.41 \pm 4.27(74)$ & $122.13 \pm 1.45(420)$ & 0.07 & 492 & 0.944 \\
\hline $\begin{array}{l}\text { Developmental speed of nymphs } \\
\text { (day) }\end{array}$ & $12.42 \pm 0.20(74)$ & $12.18 \pm 0.08(420)$ & 1.15 & 492 & 0.253 \\
\hline \multicolumn{6}{|l|}{ Mother traits } \\
\hline Date of egg laying (day) ${ }^{\mathrm{a}}$ & $36.12 \pm 1.65(49)$ & $28.98 \pm 0.47(256)$ & 4.89 & 303 & $<0.0001$ \\
\hline Weight at day $1(\mathrm{mg})$ & $51.57 \pm 0.74(49)$ & $51.73 \pm 0.37(256)$ & -0.18 & 303 & 0.857 \\
\hline $\begin{array}{l}\text { Weight gained between day } 1 \text { and } \\
\text { day } 14(\%)\end{array}$ & $16.75 \pm 1.45(49)$ & $27.86 \pm 0.74(256)$ & -6.35 & 303 & $<0.0001$ \\
\hline Pronotum area $\left(\mathrm{mm}^{2}\right)$ & $3.60 \pm 0.04(49)$ & $3.56 \pm 0.02(256)$ & 0.79 & 303 & 0.428 \\
\hline Nest building & $2.71 \pm 0.15$ & $2.50 \pm 0.06(256)$ & 1.33 & 303 & 0.184 \\
\hline Egg guarding $(\%)$ & $92.64 \pm 1.52(49)$ & $90.20 \pm 0.63(256)$ & 2.34 & 303 & 0.020 \\
\hline Food provisioning (\%) & $26.43 \pm 4.62(49)$ & $48.85 \pm 2.01$ & -4.53 & 303 & $<0.0001$ \\
\hline Family aggregation (\%) & $65.48 \pm 2.79$ (49) & $71.74 \pm 1.16(256)$ & -2.04 & 303 & 0.042 \\
\hline
\end{tabular}

$P$ values in bold remained significant after False Discovery Rate corrections (reported $P$ values are uncorrected)

a The date of egg laying was reported as the difference between the day of egg laying of each female and the first day where egg laying has been observed in the population (i.e. the 19 of October 2010) 
offs were tested partly on the whole set of 409 females with second clutches (for trade-offs involving egg-number, hatching success, embryonic developmental time) and partly in a randomly chosen sub-sample of 59 females with second clutches for trade-offs involving long-term rearing of family groups (i.e. survival rate of nymphs, nymph weight at day 1 , their weight gain from day 1 to 14 and their developmental rate). None of the measures significantly differed between this subsample and the rest of the population (all $P>0.46$ ).

Finally, reproductive isolation between offspring from $1 \mathrm{C}$ and $2 \mathrm{C}$ females in the crossbreeding experiment was tested using three independent analyses of variances (ANOVA), where the number of eggs produced in the first clutch, the subsequent number of nymphs and their weight at hatching were used as response variables, while parity background of sires and dams (their mother being $1 \mathrm{C}$ or $2 \mathrm{C}$ ) and their interaction were entered as fixed factors. To fulfil normal distribution of residuals in all our statistical analyses, hatching success, nymph survival, weight gained by mothers, egg guarding, food provisioning and family aggregations were arcsine square-root transformed, nymph, weight at day 1 was square-transformed and the date of egg laying was log-transformed. Values for parameter estimates were back transformed in tables and figures. Statistical analyses were done using the software R v2.11.1 (http://www.r-project.org/).

\section{Results}

Overall, 74 out of the 494 females $(15.0 \%)$ were attributed to $1 \mathrm{C}$ females and $420(85.0 \%)$ to $2 \mathrm{C}$ females (Fig. 1). In the subsample of females involved in food provisioning measurements, 49 out of $305(16.1 \%)$ were $1 \mathrm{C}$ females and $256(83.9 \%)$ were $2 \mathrm{C}$ females (difference: $\chi^{2}=0.17, d f=1, P=0.68$ ). The bimodal distribution of the size of second clutches relative to lifetime number of produced eggs (Fig. 1) illustrates that $1 \mathrm{C}$ and $2 \mathrm{C}$ females reflect clearly distinct modes in the distribution. $1 \mathrm{C}$ females constituted a distinct mode in the distribution (mode $=0$ ) without variance, while $2 \mathrm{C}$ females a second mode with some continuous variation around it (mode $=0.39$ ).

Parity mode of females (1C or 2C) was significantly associated with both clutch traits and maternal traits (Table 1; MANOVA on clutch traits: Wilk's lambda $=0.94$, $F_{7,486}=4.09, \quad P=0.0002$; MANOVA on maternal traits: Wilk's lambda $=0.79$, $\left.F_{8,296}=9.74, P<0.0001\right)$. In particular, the first clutches of $2 \mathrm{C}$ females contained

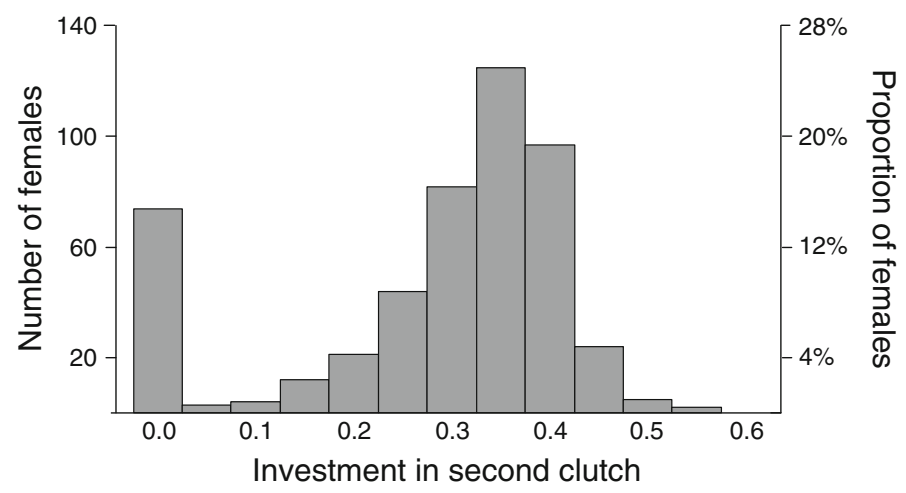

Fig. 1 Distribution of the size of second clutches relative to lifetime number of eggs produced. "0" implies no eggs in second clutches and, hence, refers to the $1 \mathrm{C}$ females 
significantly more eggs and these eggs had a significantly slower development time than the single clutch of $1 \mathrm{C}$ females (Table 1). Concerning maternal traits, $2 \mathrm{C}$ females gained significantly more weight, laid eggs significantly earlier, provided more food to their nymphs but also spend less time in egg guarding than $1 \mathrm{C}$ females (Table 1). In addition, the lifetime number of eggs produced by $2 \mathrm{C}$ females was significantly larger (by a factor of almost two) than the one produced by $1 \mathrm{C}$ females (2C females: (mean $\pm \mathrm{SE}$ ) $83.10 \pm 0.86$ eggs; $1 \mathrm{C}$ females: $46.92 \pm 1.31$ eggs; Welch $t$ test, $t=-23.07, d f=144.5, P<0.0001$ ).

Comparisons between first and second clutches of $2 \mathrm{C}$ females revealed major differences between the characteristics of first and second clutches. All taken measurements differed significantly (Table 2). Second clutches were significantly smaller (in terms of egg number), had lower survival rates (in terms of hatching success and nymph survival), but had faster development (embryonic developmental time, developmental rate of nymphs, heavier weight at hatching and larger weight gain from day 1 to 14, Table 2). Egg number, hatching success and nymph weight at day 1 were significantly and positively correlated between first and second clutches (Table 2). The other variables were not significantly correlated between first and second clutches (Table 2).

Our cross-breeding experiment confirmed the hypothesis that the observed dimorphism represented coexisting alternative life-history tactics within a single species. In the first clutches, neither the parity background of sires and dams (Fig. 2; two-way ANOVAs, all $F_{1,52}<1.7$, all $P>0.19$ ), nor their interaction significantly influenced the number of eggs laid, the number of nymphs hatched or the body mass of nymphs at hatching (interaction in two way ANOVAs; number of eggs: $F_{1,52}=0.03, P=0.87$; number of nymphs: $F_{1,52}=1.12, P=0.29$; weight of nymphs: $\left.F_{1,52}=0.06, P=0.81\right)$.

\section{Discussion}

The aim of this study was to characterise the polymorphism in the production of second clutches observed in the European earwig as coexisting alternative life-history tactics. Our large scale sampling and multivariate analysis revealed that $1 \mathrm{C}$ and $2 \mathrm{C}$ females significantly differed in a number of clutch and maternal traits, but not in terms of female morphology or quality of offspring. As compared to $1 \mathrm{C}$ females, $2 \mathrm{C}$ females laid their first clutch earlier, produced a larger first clutch and lifetime number of offspring (with a slower

Table 2 Differences between first and second clutches of $2 \mathrm{C}$ females

\begin{tabular}{|c|c|c|c|c|c|c|}
\hline & \multicolumn{4}{|c|}{ Pairwise difference } & \multicolumn{2}{|c|}{ Correlations } \\
\hline & $\begin{array}{l}\text { Mean } \\
\text { diff. } \pm \mathrm{SE}\end{array}$ & $t$ Value & $d f$ & $P$ & $r_{\mathrm{s}}$ & $P$ \\
\hline Egg number & $-21.89 \pm 0.53$ & -41.22 & 408 & $<0.0001$ & 0.43 & $<0.0001$ \\
\hline Embryonic developmental time (day) & $-6.29 \pm 0.08$ & -82.47 & 408 & $<0.0001$ & 0.06 & 0.212 \\
\hline Hatching success $(\%)$ & $-9.94 \pm 1.27$ & -7.82 & 408 & $<0.0001$ & 0.29 & $<0.0001$ \\
\hline Nymph weight at day $1(\mathrm{mg})$ & $0.17 \pm 0.03$ & 6.42 & 58 & $<0.0001$ & 0.35 & 0.007 \\
\hline Nymph survival from day 1 to day $14(\%)$ & $-14.41 \pm 2.78$ & -5.13 & 58 & $<0.0001$ & 0.09 & 0.490 \\
\hline Weight gained by nymphs until day $14(\%)$ & $43.55 \pm 6.11$ & 7.12 & 58 & $<0.0001$ & 0.02 & 0.866 \\
\hline Developmental rate of nymphs (day) & $-0.90 \pm 0.24$ & -3.80 & 58 & 0.0004 & 0.19 & 0.149 \\
\hline
\end{tabular}

Negative means (mean diff.) indicate larger values in first than second clutch. $P$ values in bold remained significant after False Discovery Rate corrections (reported $P$ values are uncorrected) 

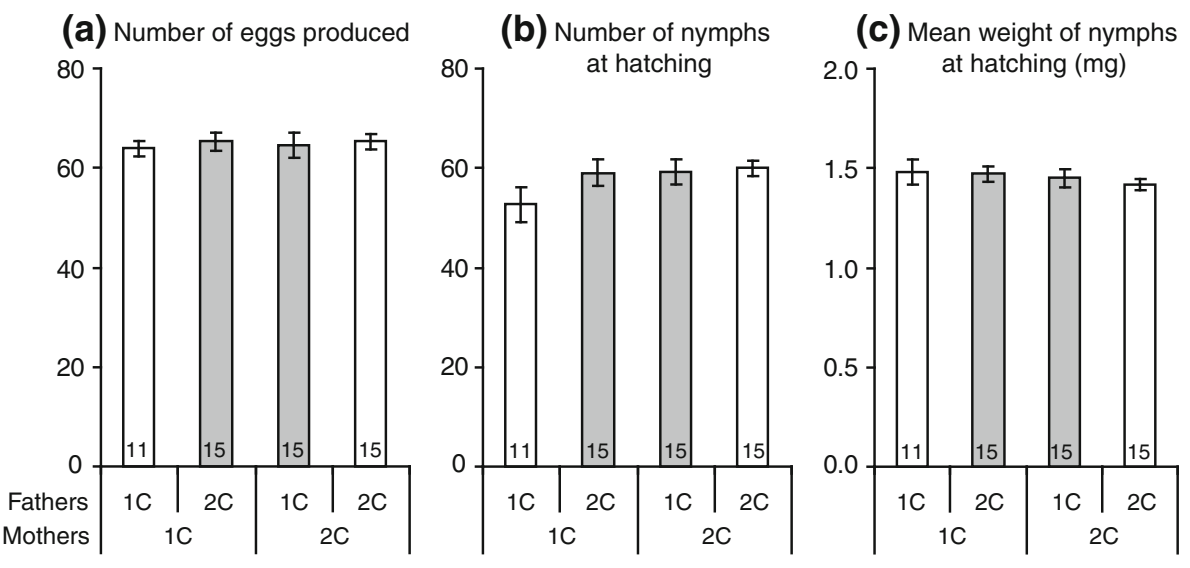

Fig. 2 Number of eggs (a), number of nymphs (b) and mean weight of nymphs (c) produced in experimental mating between adults from $1 \mathrm{C}$ and $2 \mathrm{C}$ clutches. Adults from clutches with similar (white) or alternative (grey) parity background were mated. Values are for the first clutch only. The number of mated females is at the bottom of each bar

embryonic developmental time), gained more weight during the first 14 days after hatching of first clutch, provisioned more food to their nymphs but were slightly less assiduous in egg guarding. Experimental cross-breeding also showed that mating among adult progeny of $1 \mathrm{C}$ and $2 \mathrm{C}$ females produced almost identical clutch size (eggs and nymphs) and nymphs of similar weight than $1 \mathrm{C}-1 \mathrm{C}$ and $2 \mathrm{C}-2 \mathrm{C}$ mating pairs. This finding clearly indicates that discontinuous distribution of investment in second clutches represent coexisting alternative life-histories tactics within a single species, rather than divergent life-histories of two sympatric sister species present in the studied population.

The 2-fold lower level of maternal care (in terms of food provisioning) reported in $1 \mathrm{C}$ as compared to $2 \mathrm{C}$ females contrasts with predictions that reduced costs of care in terms of future reproduction should favour enhanced maternal investment towards the current offspring (Gilbert and Manica 2010; Tallamy and Brown 1999). Hence, semelparity appears not to be a strict precondition for the evolution and maintenance of maternal care (Tallamy and Brown 1999). Our results also revealed that access to ad libitum food did not homogenise the level of maternal care provided to current offspring as would be expected if the level of care was determined by benefits and costs as mediated by concurrent conditions. This suggests that variation in maternal care at least partly depends on factors independent from food availability, such as intrinsic female or nymph quality (e.g. Mas et al. 2009), or variation maintained by coadaptation between maternal care and offspring traits (which would contribute to the maintenance of intrinsic variation in maternal care, Kölliker et al. 2005).

Our findings are not consistent with the hypothesis that $1 \mathrm{C}$ and $2 \mathrm{C}$ females reached equivalent fitness over lifetime through alternative investment trade-off between current and future reproduction. This interpretation is further supported by the result that egg number, hatching success and nymph weight at day 1 were positively correlated between first and second clutches. The lack of evidence for trade-offs between first and second clutches has to be interpreted with caution, however. Subtle trade-offs could indeed be covered and reversed when individuals vary in quality and potential for reproductive output (house-car principle, van Noordwijk and de Jong 1986). These trade-offs may also 
be harder to observe due to the low cost of maternal care when individuals are reared under standardised laboratory conditions such as with easy access to food and in the absence of predators and pathogens (Kölliker and Vancassel 2007; Little et al. 2003; Stearns 1992). For instance, we cannot rule out the possibility that under predation pressure, offspring of $1 \mathrm{C}$ females would have had higher survival because $1 \mathrm{C}$ females spent more time or effort in protecting their young against predators.

The production of single clutches by $1 \mathrm{C}$ females is unlikely to simply reflect limitations in critical resources for reproduction, such as female viability, age at reproduction, senescence after clutch production or sperm depletion. First, 62 out of the $74(83.8 \%) 1 \mathrm{C}$ females survived until the end of the experiment (i.e. 60 days post-hatching), indicating that single clutch production was not a mere consequence of premature death of these females. Second, $1 \mathrm{C}$ and $2 \mathrm{C}$ females were likely to be of a similar age in the experiment, as all individuals moulted into adults within a period of approximately two weeks. Third, 1C females were unlikely to already be in a state of senescence after having produced their clutch, as it was produced only 8 days later on average than the first clutch of $2 \mathrm{C}$ females and the average latency between the successive clutches of $2 \mathrm{C}$ females was 37 days. Finally, single clutch production was unlikely to result from enhanced sperm limitation in $1 \mathrm{C}$ than $2 \mathrm{C}$ females (e.g. due to a lower number of mating partners), as previous paternity analysis using microsatellite markers reported that a similar number of males sired progeny from 1C and 2C females (Guillet 2000). Furthermore, mating is not a prerequisite for oviposition in $F$. auricularia, and females lay their clutches also if the eggs are not fertilized, for instance due to lack of sperm (M.K. unpubl. results).

Alternatively, the coexistence of $1 \mathrm{C}$ and $2 \mathrm{C}$ females could reflect alternative lifehistories where females adopt the tactic that provides the highest fitness returns given her condition and according to an evolved threshold (Gross 1996; Tomkins and Brown 2004). Thereby, condition can be a property of the individual female itself (what is usually meant by "condition"; e.g., nutritional, genetic, ontogenetic or environmental influences on reproductive capacity), but might also reflect the outcome of interactions between the female and her social environment, such as specific properties of their male mates or of the tended offspring (Wolf et al. 1998). Consistent with a role of female condition in underlying the observed discrete variation in clutch production, we found that $2 \mathrm{C}$ females gained significantly more weight during nymph care than $1 \mathrm{C}$ females. This finding could reflect that $2 \mathrm{C}$ females chose their reproductive tactic before or during care for their first clutch, putting more effort in increasing their weight in order to produce a second clutch. Alternatively, 1C females may have been limited in their ability to gain weight for secondclutch production because of their intrinsic physical condition, or because of properties of their social environment (i.e., mates, offspring). However, further research is required to elucidate the determinism of the $1 \mathrm{C}-2 \mathrm{C}$ dimorphism in $F$. auricularia.

In 2C (iteroparous) females, all the measured characteristics of second clutches significantly differed from the ones of first clutches. In particular, second clutches showed faster development, larger nymph weight at hatching, higher weight gain, but lower survival. Ultimately, the development of nymphs is expected to be faster in second than in first clutches as it may help to (1) alleviate to some degree cannibalism risk caused by offspring from first clutches (second clutch nymphs have to survive in an environment populated by advanced instars nymphs from first clutches, Vancassel and Quris 1994), (2) catch up in development to be able to effectively compete with offspring from first clutches for mating when adult and (3) oviposit before winter starts. Proximately, this enhancement of growth rate could be mediated by different mechanisms: for instance, a maternal effect may induce different developmental programs in first as compared to second clutches, or the 
expectedly higher levels of maternal care for second clutches may have such an effect on developmental rate (i.e. terminal investment, Williams 1966). Alternatively, it is possible that a higher cannibalism rate in second than first clutches may explain this result. Because mortality in earwig clutches is almost always associated with cannibalism (Dobler and Kölliker 2010), our finding of significantly lower survival rate together with higher weight gain of nymphs in second than first clutches are consistent with the hypothesis that cannibalism is higher in second clutches.

It is characteristic for alternative allocation phenotypes (Brockmann and Taborsky 2008) that the frequency of the different tactics varies among populations due to ecological and population dynamic factors. For example, the relative frequency of two coexisting wing-morphs (reflecting alternative dispersal tactics) in the planthopper Prokelisia marginata depends on population density and environmental persistence (Denno et al. 1996), with an average of $92 \%$ of the dispersing morph in populations along the North American Atlantic coast and $17 \%$ in populations along the Gulf of Mexico. Although we lack a quantitative analysis of variation in the parity dimorphism across populations in earwigs, the example of the wing-dimorphism in $P$. marginata illustrates that the relative frequencies for the $1 \mathrm{C}$ and $2 \mathrm{C}$ life-histories in our study (i.e. 15 and $85 \%$, respectively) is in a range that can be expected for an alternative allocation phenotype.

The frequency of the $2 \mathrm{C}$ tactic in the Mediterranean population studied here $(85 \%)$ was substantially higher than in a more northern and higher altitude, central Swiss, population (approx. 33\%, Kölliker 2007), and similar to a low-altitude (albeit northern) population near Rennes (Bretagne, France) (86\%; Vancassel 1984). Previous studies suggested season length and population density as likely major agents of selection on mode of parity. Short seasons (i.e., at high altitude and/or latitude) were expected to provide less time to successfully raise two clutches and therefore to selectively favour the 1C tactic (Charlesworth 1994; Stearns 1992), whereas long seasons allow longer reproductive periods which may favour the 2C tactic (Vancassel 1984). High population densities are also predicted to favour the $1 \mathrm{C}$ tactic because of the higher risks of cannibalism for second clutch nymphs by the older first clutch nymphs, which differentially reduces the juvenile survival rate and, hence, reproductive value for second clutch nymphs (Moerkens et al. 2009). The known differences in seasons between Mediterranean and Swiss climates are consistent with the season length hypothesis and could explain the observed differences in the frequency of $2 \mathrm{C}$ tactic between populations. Density estimates for the two populations are however not available. In the future, transplant experiments within and between populations of different density and/or season length may shed light on the selective agents and evolutionary dynamics underlying the coexisting $1 \mathrm{C}$ or $2 \mathrm{C}$ life-history tactics in earwig populations.

To conclude, our results demonstrate that semelparous and iteroparous modes of reproduction coexist in $F$. auricularia populations, most likely as condition-dependent alternative female life-history tactics. Overall, $15 \%$ of females did not produce second clutches despite access to ad libitum food and absence of predators. This observation suggests that the alternative life-history tactics may not be completely phenotypically plastic, but may also contain a heritable component. To shed light on the mechanism expressing the $1 \mathrm{C}-2 \mathrm{C}$ dimorphism, further experiments will be required manipulating early (juvenile) and late (adult) nutritional condition, and/or breeding experiments to disentangle environmental from genetic sources and the role of social interactions with mates and offspring in generating variation in the expression of the alternative modes of parity. 
Acknowledgments We thank Ralph Dobler and Flore Mas for help during the experiments, Lisa Bradbury, Elodie Belz and three anonymous referees for comments on the manuscript and the Swiss National Science Foundation for financial support (grant-no. PP00A-119190 to MK).

\section{References}

Benjamini Y, Hochberg Y (1995) Controlling the false discovery rate- a practical and powerful approach to multiple testing. J R Stat Soc Ser B (Statistical methodology) 57:289-300

Brockmann HJ, Taborsky M (2008) Alternative reproductive tactics and the evolution of alternative allocation phenotypes. In: Oliveira RF, Taborsky M, Brockmann HJ (eds) Alternative reproductive tactics. Cambridge University Press, Cambridge, pp 25-51

Bulmer MG (1985) Selection for iteroparity in a variable environment. Am Nat 126:63-71

Charlesworth B (1994) Evolution in age-structured populations. Cambridge University Press, Cambridge

Charnov EL, Schaffer WM (1973) Life-history consequences of natural-selection-Coles result revisited. Am Nat 107:791-793

Choe JC, Crespi BJ (1997) The evolution of social behavior in insects and arachnids. Cambridge University Press, Cambridge

Clutton-Brock TH (1991) The evolution of parental care. Princeton University Press, Princeton

Cole LC (1954) The population consequences of life history phenomena. Q Rev Biol 29:103-137

Costa JT (2006) The other insect societies. Harvard university press, Cambridge and London

Crespi BJ, Teo R (2002) Comparative phylogenetic analysis of the evolution of semelparity and life history in salmonid fishes. Evolution 56:1008-1020

Denno RE, Roderick GK, Peterson MA, Huberty AF, Dobel HG, Eubanks MD, Losey JE, Langellotto GA (1996) Habitat persistence underlies intraspecific variation in the dispersal strategies of planthoppers. Ecol Monogr 66:389-408

Dobler R, Kölliker M (2010) Kin-selected siblicide and cannibalism in the European earwig. Behav Ecol 21:257-263

Gilbert JDJ, Manica A (2010) Parental care trade-offs and life-history relationships in insects. Am Nat $176: 212-226$

Grosberg RK (1988) Life-history variation within a population of the colonial ascidian Botryllus schlosseri. I. The genetic and environmental control of seasonal variation. Evolution 42:900-920

Gross MR (1996) Alternative reproductive strategies and tactics: diversity within sexes. Trends Ecol Evol 11:92-98

Guillet S (2000) Origines et conséquences de l'évolution des cycles de vie chez les Dermaptères: le cas de Forficula auricularia L. (Forficulidae). PhD thesis, Université Rennes I, Rennes

Guillet S, Guiller A, Deunff J, Vancassel M (2000) Analysis of a contact zone in the Forficula auricularia L. (Dermaptera: Forficulidae) species complex in the Pyrenean Mountains. Heredity 85(Pt 5):444-449

Iguchi K, Tsukamoto Y (2001) Semelparous or iteroparous: resource allocation tactics in the ayu, an osmeroid fish. J Fish Biol 58:520-528

Kölliker M (2007) Benefits and costs of earwig (Forficula auricularia) family life. Behav Ecol Soc 61:1489-1497

Kölliker M, Vancassel M (2007) Maternal attendance and the maintenance of family groups in common earwigs (Forficula auricularia): a field experiment. Ecol Entomo 32:24-27

Kölliker M, Brodie ED, Moore AJ (2005) The coadaptation of parental supply and offspring demand. Am Nat $166: 506-516$

Lamb RJ (1975) Effects of dispersion, travel, and environmental heterogeneity on populations of the earwig Forficula auricularia L. Can J Zool 53:1855-1867

Leggett WC, Carscadden JE (1978) Latitudinal variation in reproductive characteristics of american shad (Alosa-sapidissima) — evidence for population specific life-history strategies in fish. J Fish Res Board Can 35:1469-1478

Little TJ, O'Connor B, Colegrave N, Watt K, Read AF (2003) Maternal transfer of strain-specific immunity in an invertebrate. Curr Biol 13:489-492

Liu Z (1991) Le groupement familial chez Forficual auricularia, L. (insecte, dermaptere): étude causale et fonctionelle. Université de Rennes I, Rennes

Mas F, Kölliker M (2008) Maternal care and offspring begging in social insects: chemical signalling, hormonal regulation and evolution. Anim Behav 76:1121-1131

Mas F, Kölliker M (2011) An offspring signal of quality affects the timing of future parental reproduction. Biol Lett 7:352-354 
Mas F, Haynes KF, Kölliker M (2009) A chemical signal of offspring quality affects maternal care in a social insect. Proc R Soc B Sci 276:2847-2853

Moerkens R, Leirs H, Peusens G, Gobin B (2009) Are populations of European earwigs, Forficula auricularia, density dependent? Entomol Exp Appl 130:198-206

Moerkens R, Leirs H, Peusens G, Gobin B (2010) Dispersal of single- and double-brood populations of the European earwig, Forficula auricularia: a mark-recapture experiment. Entomol Exp Appl 137:19-27

Quinn G, Keough M (2002) Experimental design and data analysis for biologists. Cambridge University Press, Cambridge

Ranta E, Kaitala V, Alaja S, Tesar D (2000a) Nonlinear dynamics and the evolution of semelparous and iteroparous reproductive strategies. Am Nat 155:294-300

Ranta E, Tesar D, Alaja S, Kaitala V (2000b) Does evolution of iteroparous and semelparous reproduction call for spatially structured systems? Evolution 54:145-150

Ranta E, Tesar D, Kaitala A (2002) Environmental variability and semelparity vs iteroparity as life histories. J Theor Biol 217:391-396

Seamons TR, Quinn TP (2010) Sex-specific patterns of lifetime reproductive success in single and repeat breeding steelhead trout (Oncorhynchus mykiss). Behav Ecol Soc 64:505-513

Staerkle M, Kölliker M (2008) Maternal food regurgitation to nymphs in earwigs (Forficula auricularia). Ethology 114:844-850

Stearns SC (1976) Life-history tactics—review of ideas. Q Rev Biol 51:3-47

Stearns SC (1992) The evolution of life histories. Oxford University Press, Oxford

Stegmann UE, Linsenmair KE (2002) Assessing the semelparity hypothesis: egg-guarding and fecundity in the Malaysian treehopper Pyrgauchenia tristaniopsis. Ethology 108:857-869

Taborsky M, Oliveira RF, Brockmann HJ (2008) The evolution of alternative reproductive tactics: concepts and questions. In: Oliveira RF, Taborsky M, Brockmann HJ (eds) Alternative reproductive tactics. Cambridge University Press, Cambridge, pp 1-21

Tallamy DW, Brown WP (1999) Semelparity and the evolution of maternal care in insects. Anim Behav 57:727-730

Tallamy DW, Wood TK (1986) Convergence patterns in subsocial insects. Ann Rev Ent 31:369-390

Tomkins JL, Brown GS (2004) Population density drives the local evolution of a threshold dimorphism. Nature 431:1099-1103

Tomkins JL, Simmons LW (1998) Female choice and manipulations of forceps size and symmetry in the earwig Forficula auricularia L. Anim Behav 56:347-356

van Noordwijk AJ, de Jong G (1986) Acquisition and allocation of resources: their influence on variation in life history tactics. Am Nat 128:137-142

Vancassel M (1984) Plasticity and adaptive radiation of dermapteran parental behavior-results and perspectives. Adv Stud Behav 14:51-80

Vancassel M, Quris R (1994) Differential release of diapause in the earwig Forficula auricularia as indicator of respective contribution of two cohorts to the reproductive generation. Acta Oecol 15:63-70

Williams GC (1966) Adaptation and natural selection: a critique of some current evolutionary thought. Princeton University Press, Princeton

Wirth T, Le Guellec R, Vancassel M, Veuille M (1998) Molecular and reproductive characterization of sibling species in the European earwig (Forficula auricularia). Evolution 52:260-265

Wolf JB, Brodie Iii ED, Cheverud JM, Moore AJ, Wade MJ (1998) Evolutionary consequences of indirect genetic effects. Trends Ecol Evol 13:64-69 